\title{
Multilocular Thymic Cyst with Superior Cava Vein Syndrome Complication
}

\author{
Rahadi Widodo ${ }^{1 *}$, Ngakan Putu Putra ${ }^{1}$, Soebagjo ${ }^{2}$, Arief Iskandar ${ }^{3}$ and Mudjiwijono ${ }^{4}$ \\ ${ }^{1}$ Pulmonology and Respiratory Department, Saiful Anwar Hospital, Brawijaya University, Jaksa Agung Suprapto 2, Malang, 65112, Indonesia \\ ${ }^{2}$ Thoracic Surgery Department, Saiful Anwar Hospital, Brawijaya University, Jaksa Agung Suprapto 2, Malang, 65112, Indonesia \\ ${ }^{3}$ Radiology Department, Saiful Anwar Hospital, Brawijaya University, Jaksa Agung Suprapto 2, Malang, 65112, Indonesia \\ ${ }^{4}$ Pathology Department, Saiful Anwar Hospital, Brawijaya University, Jaksa Agung Suprapto 2, Malang, 65112, Indonesia
}

\begin{abstract}
Background: Thymic cysts are uncommon, only comprising 1-3\% of all mediastinal masses and 5-28\% of the mediastinal cysts. Usually benign entities representing remnants of persistent thymopharyngeal duct or cystic degeneration of Hassall corpuscles. Unilocular thymic cysts are probably of congenital origin (derived from embryologic thymic tissue) and without inflammation, while multilocular thymic cysts are predominantly acquired, resulting from inflammation or neoplasm, have thick walls and contain dark-brown fluid.

Case: A 51-year-old male with complaint of pain on his neck, shoulder, and right chest, accompanied with swelling of right arm and vena ecstasis on his neck and chest wall. The patient was diagnosed as anterior mediastinal tumor with complication vena cava superior syndrome. He underwent surgical treatment with approach median sternotomy and wide excision of tumor. Histopathologic examinaton of the tumor reveals a multilocular thymic cyst. Pneumonia occured after surgery and could be overcome by aggresive combination antibiotic treatment. There was right pleural effusion and right phrenic nerve paralysis after surgery. In this patient, also there is a mass in right posterior pleural cavity which has not been removed by surgical treatment.
\end{abstract}

MRJ 2019; 1(1):26-33

Keywords: mediastinal tumors, thymic cysts, sternotomy

\section{Introduction}

Mediastinal tumors are tumors in the mediastinum that is the cavity between the right and left lungs. Mediastinum contains the heart, arteries, veins, trachea, thymus gland, nerves, connective tissue, and lymph nodes. ${ }^{1}$

Data on the frequency of mediastinal tumors in Indonesia, among others, were obtained from Thoracic Surgery Department, Persahabatan Hospital, Jakarta and RSUD Dr. Sutomo Surabaya.
During the years 1970-1990 in the Persahabatan Hospital surgeries were performed on 137 cases, the types of tumor found were teratoma (32.2\%), thymoma (24\%), nerve tumors (8\%), and lymphoma (4.3\%). In Dr. Soetomo Hospital explained the location of the tumor in the anterior mediastinum was on $67 \%$ of cases, medial mediastinum $29 \%$ and in the posterior mediastinum 25.5\%. From overseas literature it is known that the types that are found in anterior mediastinal tumors are

\footnotetext{
*Corresponding author: Rahadi Widodo (rahadiwidodo@ymail.com)

Pulmonology and Respiratory Department, Saiful Anwar Hospital - Brawijaya University, Jaksa Agung Suprapto St. No. 2, Malang. 65112 , Indonesia 
Lymphoma, Thymoma and Germ Cell Tumors. ${ }^{1}$

The cysts in the mediastinum, which are benign masses, are rare but important diagnostic group that covers $12-18 \%$ of all primary tumors in the mediastinum. A physician has little chance to recognize the clinical symptoms and the presence of the disease because it is relatively rare. Only a few reports that review all types of mediastinal cysts. Classification of mediastinal cysts based on their etiology includes bronchogenic cysts and esophageal duplication cysts derived from foregut, pleural / pericardial cyst which are derivatives of mesothelium, cysts of the thymic (thymic cysts), and other cysts. ${ }^{2}$

Because the thymus is located in the anterior mediastinum and basically is the main structure there, most tumors in the anterior mediastinum are one of the derivatives of the thymus, or at least closely related to the thymus ${ }^{3}$. The first description of a tumor of the thymus was in 1832 by Sir Astley Paston Cooper, a surgeon from London. In 1849 Arthur Hill Hassall, a British microscopist, described the presence of a unique corpuscle in the thymus (Hassall's corpuscle). The first thymectomy to treat myasthenia gravis was done in 1911 by Ferdinand Sauerbruch in Zurich, Switzerland. ${ }^{4}$

Thymic cysts are rarely found and found in only $1 \%$ of the total mass in the mediastinum. These cysts can be congenital or acquired. Congenital thymic cysts are rare and derivatives of persistent thymopharyngeal duct. About 50\% of congenital thymic cysts are discovered accidentally in the first 2 decades of life. Acquired thymic cysts can occur together with other tumors in the thymus, after radiation therapy for Hodgkin's Disease, or after thoracotomy. These cysts can be unilocular or multilocular. Multilocular thymic cysts are sequelae of various inflammatory processes and usually occur without symptoms (asymptomatic) in male. $^{5}$

\section{Case}

A 51 year-old male. Came with complaints of pain in the neck, shoulders, to the right chest since 3 years before the admission and worsening. The face and neck to the right arm swell when doing strenuous activities.

From physical examination there is swelling in the face, neck, shoulders, and right arm and signs of venous ectasis. The right hemithorax appears more convex and the motion of the breath is left behind. Stem fremitus decreases, percussion is faint, and breathing sounds decrease in the right middle and lower hemithorax.

From laboratory examination there were leucocytosis (leucocytes 13,400 / mm3). 
Electrocardiogram examination: sinus tachycardia HR $113 \mathrm{x} /$ minute.

Spirometry result: moderate degrees of restriction and moderate degrees of obstruction.

Chest $X$ ray examination (Figure 1): Right anterior mediastinal mass.
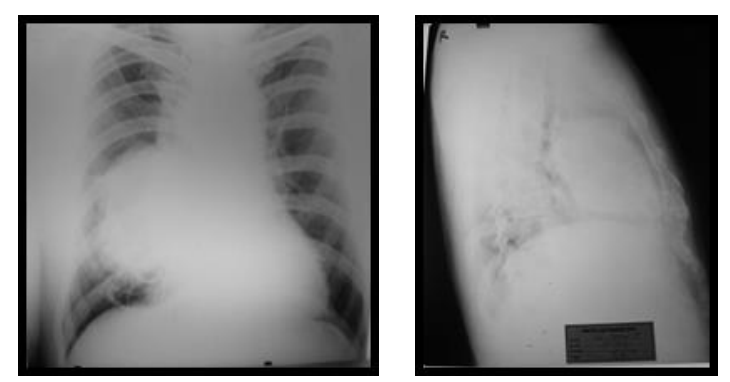

Figure 1. Chest X Ray, taken on July $28^{\text {th }}$, 2010. Show right anterior mediastinal mass.

Thoracic CT Scan (Figure 2): External anterior mediastinal tumor with extension to the right pleural, suggestive of malignant suspect teratoma with differential diagnose thymoma $\approx \mathrm{T} 1 \mathrm{~N} 0$ M1.
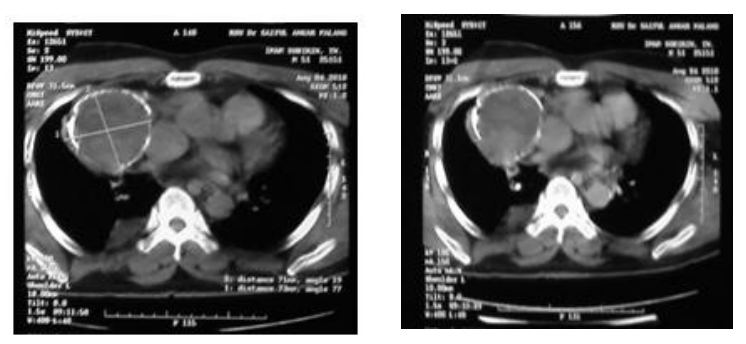

Figure 2. Thoracic CT Scan, taken on August $5^{\text {th }}$, 2010. Show right anterior mediastinal mass.

Based on the above data, the patient was diagnosis as an right anterior mediastinal tumor suspect teratoma with differential diagnose tumor of the thymus or

malangrespiratoryjournal.org| lymphoma, with complications of superior cava vein syndrome.

The patient underwent surgery with sternotomy approach and tumor wide excision (Figure 3).
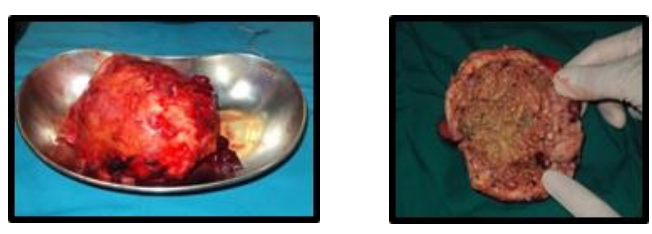

Figure 3. Tumor after excision, Left: tumor with size: 10 x 7 x $5 \mathrm{~cm}$; Right: Center of the cyst

After surgery the patient was admitted to the ICU and backed up with a ventilator.

Endotracheal tube was removed on the 6th postoperative day and the patient was discharged from the ICU on the 7th postoperative day. Patients are allowed to go home on the 10th day after surgery. At the time the patient came home still got symptoms of swelling in the right arm.

\section{Discussion}

A 51-year-old male was reported with a diagnosis of right anterior mediastinal tumor et causa multilocular thymic cyst with complications of superior cava vein syndrome and right phrenic nerve paralysis, and pleural effusion after sternotomy and tumor excision. The diagnosis was made on the basis of history, physical examination, and laboratory finding. This case is a very rare, some 
published reports mention that thymic cyst is only about $1-3 \%$ of the total mass in the mediastinum. $^{6,7}$

Although there are no epidemiological data on the sex of patients suffering from thymic cyst due to the rarity of this case, but published data from the thymic cyst case report shows that most of this disease are male, the same as in this case. Thymic cyst is usually found in the age between the $30 \mathrm{~s}$ to $60 \mathrm{~s}^{8}$, according to the age of this patient (51 years). These patients belong to the age group above 40 years, which is based on reference usually mediastinal tumors at this age is asymptomatic and only one third that shows symptoms, and also one third of mediastinal tumors in this age group are malignant. ${ }^{9}$

Although when compared with the age group of $20-40$ years $( \pm 50 \%$ of malignant cases) the likelihood of malignancy in this age group is smaller, but based on the presence of clinical symptoms and the location of the mass, the possibility of malignancy in these patients must still be considered. Malignant masses are only about $15 \%$ are asymptomatic ${ }^{9}$. In patients with malignancy: $85 \%$ show symptoms, while benign neoplasms are only $46 \%{ }^{10}$. This patient complained of neck, shoulder, right chest pain since \pm 3 years before hospital admission, and at the time of the first examination at the hospital had shown signs of superior cava vein syndrome. The location of the mass in the anterior mediastinum is also more likely to be malignant $(59 \%$, compared to $29 \%$ and $16 \%$ in the middle and posterior mediastinum). ${ }^{10}$

Symptoms of chest pain as experienced by this patient in this case can indeed occur in thymic cyst. The report Takeda et al (2003) states that chest pain in patients with thymic cyst is the most common symptom, as many as 6 out of $30(20 \%)$ patients were observed, followed by hoarseness (13.3\%), shortness of breath (10\%), cough (6.6\%), and dysphagia (3.3\%). This patient does not complain of hoarseness and dysphagia, but only a bad taste in the throat accompanied by tightness and swelling of the neck to the right arm when doing heavy activities, which can be associated with superior cava vein syndrome.

Superior cava vein syndrome - which in this case is characterized by swelling in the neck, shoulders, and right arm and vein ecstasis that appears on the neck and chest of the patient, as well as in the trachea that appears through the bronchoscopy can occur due to invasion by the tumor to the structure around it, including the superior cava vein. This is possible because the size of the mass is quite big $(10 \times 7 \times 5 \mathrm{~cm})$. In this case a high right diaphragm was also found, possibly due to diaphragm paralysis, which was more clearly seen after the mass in the anterior mediastinum 
was removed. This could be a local symptom due to tumor invasion into the right phrenic nerve, or it could be due to injury to the phrenic nerve as a complication of sternotomy surgery and tumor removal in the thymus. According to the notes of Hussain et al (2010) intraoperative complications occur in about 9\% of patients who underwent sternotomy. Superior cava vein syndrome and phrenic nerve paralysis are rarely found in patients with tumors / cysts of the thymus, but are often indicative of malignant disease. ${ }^{9}$

Examination of right and lateral thoracic PA radiographs showed a clearly demarcated mass in the anterior right mediastinum, which was clarified with a CT scan with and without contrast showing an isohypodense heterogeneous solid mass with cystic parts inside, firm boundaries, regular margins with calcifications at the edges, the size $\pm 71 \times 73 \times 80 \mathrm{~mm}$ which forms a blunt angle in the right lung, in the antero-superior superior mediastinum, with the addition of contrast, it seems that heterogeneous strong enhancement especially on the solid part. Also visible solid mass (density 52 HU) firm boundary, regular edges, broadbased on the posterior side of the right pleural with the addition of the contrast does not enhanced. Based on this examination the patient was diagnosed as an anterosuperior right mediastinal tumor with extension to the right pleural (suggestive malignant). This description can be a tumor / cyst of the thymus, but other possibilities as a differential diagnosis are still many.

In this case, operative therapy was chosen with a median sternotomy approach and wide tumor excision. At the time of the operation, a $10 \times 7 \times 5 \mathrm{~cm}$ tumor was found in the right anterior mediastinum which forced the lungs especially the inferior and middle lobes, also urged the mediastinum so that the superior cava vein was squashed. Benign tumor impression. Macroscopically these tumors are oval shaped, in the form of cysts with thick walls, brownish in color, containing material such as a yellow-turbid brownish. This description is similar to the multilocular thymic cyst as in the literature ${ }^{3,6,11}$. Microscopically, the tissue is mostly necrotic, with cavity formation, without the epithelium of the lining clearly visible, in some parts it is found as dense lymphoid cells. There are no malignancies in this preparation. This strengthens the diagnosis of multilocular thymic cyst.

After surgery the patient was admitted to the ICU and backed up with a ventilator. One day after surgery the chest X-ray showed a picture of unclear boundary intercourse at the paracardial nerve, which could be suspected as pneumonia with a differential diagnosis of residual mediastinal tumors. The occurrence of 
leucocytosis up to $17,200 / \mathrm{mm} 3$ (and a day later increased to $23,400 / \mathrm{mm} 3$ ) strengthens the suspicion of pneumonia so that antibiotics were given more aggressively with meropenem $3 \times 1$ gram iv plus gentamycin 1x320 mg iv. Pneumonia that occurs in this case was categorized as hospital-acquired pneumonia (HAP) but not ventilator-associated pneumonia (VAP) because it occurs less than 48 hours after intubation and ventilator. Post-operative sternotomy is also had a possibility to poststernotomy mediastinitis which is a complication with high mortality. Aggressive combination antibiotics in this case turned out to give good results with clinical improvement on the 5th day of the surgery, leukocytosis decreased to $17,300 / \mathrm{mm} 3$ and an improved of the chest $\mathrm{X}$-ray picture was characterized by reduced infiltrate in the paracardial.

PA chest radiograph on September $14^{\text {th }}$ 2011 found opacity in the lower right lung area and pleural effusion was suspected. Pleural effusion was only evacuated 2 months later because the patient did not visit to the pulmonary clinic again because he felt no complaints anymore. The patient came to the pulmonary clinic on November $2^{\text {nd }} 2011$ after starting to feel complaints of shortness of breath and nausea especially when on the move. Physical examination showed that left hemithorax breath was left behind, faint percussion and decreased breath sounds in the lower right hemithorax. No more swelling in the patient's right arm. Chest radiograph on November $1^{\text {st }} 2011$ shows a picture of opacity in the lower right lung area like chest radiograph on September $9^{\text {th }} 2011$. From the proef punctie obtained (+) results in the form of clear-yellow liquid. Then a thoracentesis is performed to evacuate the pleural fluid. On November $2^{\text {nd }} 2011$, it was obtained $500 \mathrm{cc}$ (stopped) and repeated on November $9^{\text {th }} 2011$, there was $300 \mathrm{cc}$ (stopped traffic), so a total of 800 cc was yellow-brown liquid. On November $22^{\text {nd }} 2011$ the results of the negative punctie proef were confirmed by thoracic ultrasound on November $23^{\text {rd }} 2011$ showed that there was no pleural effusion.

Pleural fluid analysis shows that the fluid is an exudate characterized by high leukocyte content, more than 1,000 / mm3 $(10,980 / \mathrm{mm} 3)$, high protein content, more than $3 \mathrm{gr} / \mathrm{dl}$ (4.98 g / dl), high LDH levels , more than 200 IU / L (445 IU / L), pleural fluid $\mathrm{LDH}$ ratio compared to serum $\mathrm{LDH}>$ 0.6 (pleural fluid LDH: serum LDH $=445$ : $720=0.618)$ and positive Rivalta Test results. If the pleural fluid is in the form of an exudate, it can be suspected that the cause is local processes in the pleura and its surroundings. Possible causes are: (1) Complications of sternotomy surgery and wide excision of the tumor that may cause injury to the pleura resulting in 
inflammation that can lead to effusion; (2) Complications of pneumonia that occur postoperatively; (3) Complications of tumors in the right posterior hemithorax from the chest CT scan on December $9^{\text {th }}$ 2011 were present in the posterior right pleural cavity. Pleural fluid culture results did not obtain germ growth (aerobes) and pleural fluid cytology class II.

Thoracic radiograph on November $9^{\text {th }} 2011$ post evacuation of pleural fluid totaling $800 \mathrm{cc}$ obtained a picture of mass in the right inferior hemithorax, with firm boundaries forming blunt angles, lobulated form. Also visible is thin-walled cavity with air fluid level in it in the anterior right lung, and thin-walled cavity in the posterior side, which can be pneumatocele with secondary infection. From the thoracic ultrasound November 23 2011 no pleural effusion was seen anymore. To evaluate the mass in the hemithorax that appears on the chest radiograph, a chest CT scan was performed on December $9^{\text {th }}$ 2011 followed by transthoracal FNAB with ultrasound guidance on December $28^{\text {th }}$ 2012.

From the thoracic CT scan, a heterogeneous solid mass, firm boundary, lobulated, showed a posterior right pleural cavity, accompanied by right pleural effusion. Compared to CT scan on August $4^{\text {th }} 2010$ the mass size has increased. Histopathological examination results malangrespiratoryjournal.org| through FNAB (Fine Needle Aspiration Biopsy) with ultrasound guidance failed to find any signs of malignancy in this lesion. FNAB smears contain small size lymphoid cells, cells with oval nuclei and cyst macrophage, and no apparent atypical cells are seen. It was concluded that this lesion was likely a lymphoid tissue with cyst formation. Many tumors / cysts in the posterior mediastinum can resemble this, including lymphoma. Thymic cyst is a benign lesion, but many published case reports have described cases of thymic cyst accompanied by other neoplasms such as mature teratoma, squamous cell carcinoma, Hodgkin's Disease, thymoma or thymic carcinoma, neurofibromatosis, etc. Certainty histopathological diagnosis may be obtained if surgery is performed on the mass.

\section{Conclusions}

A case of a 51-year-old man who was diagnosed with an anterior mediastinal due to multilocular thymic cyst tumor with complications of superior cava vein syndrome has been reported. In this case, operative therapy with a sternotomy approach and tumor wide excision was performed. At the time of the operation, an oval-shaped tumor with a diameter of 10 $\mathrm{cm}$ in the right anterior mediastinum, in the form of a cyst with a thick, brownish color wall, contains material such as a yellow- 
turbid brownish. Histopathological examination concluded as multilocular thymic cyst. Postoperatively, there are signs of pneumonia based on chest radiograph and leucocytosis, which improves after the administration of aggressive combination antibiotic therapy. Signs of superior cava vein syndrome were improved postoperatively, but then right pleural effusion also occurs, and elevation of the right diaphragm was likely due to paralysis of the right phrenic nerve. In this patient there was also a mass in the posterior right pleural cavity that had not been operated on, so the possibility of another neoplasm - benign or malignant that accompanies a thymic cyst still cannot be completely excluded.

\section{References}

1. Perhimpunan Dokter Paru Indonesia, 2003. Tumor Mediastinum (Tumor Mediastinum Nonlimfoma) Pedoman Diagnosis \& Penatalaksanaan di Indonesia. Jakarta: Perhimpunan Dokter Paru Indonesia.

2. Takeda S, Miyoshi S, Minami M, Ohta M, Masaoka A, and Matsuda H, 2003. Clinical Spectrum of Mediastinal Cysts. Chest. Vol 124, pp:125-132.

3. den Bakker MA, and Oosterhuis JW, 2009. Tumours and Tumour-like Conditions of the Thymus other than Thymoma; a Practical Approach. Histopathology. Vol 54, pp: 69-89.
4. Chahinian AP, 1998. Thymomas and Thymic Tumors, in Neoplasms of the Thorax. 1998. Section 28, Chapter 90. page 1313-1318.

5. Jeung MY, Gasser B, Gangi A, Bogorin A, Charneau D, Wihlm JM, Dietemann JL, and Roy C, 2002. Imaging of Cystic Masses of the Mediastinum. RadioGraphics. Vol 22, pp: S79-S99.

6. Constantacos C, Lawson NM, Votanopoulos KI, Olutoye O, Eldin KW, and Feigin RD, 2007. Giant Thymic Cyst in Left Lower Hemithorax of a Healthy Teenaged Athlete. J Thorac Cardiovasc Surg. Vol 134, pp:1373-1374.

7. Im SI, Park SJ, Kho JS, Lee JH, Choi BR, Kim JW, Kwak CH, and Hwang JY, 2007. A Case of Thymic Cyst in the Middle Mediastinum Mimicking Pericardial. J Cardiovasc Ultrasound. Vol 15(2), pp:40-42.

8. Tiveron MG, Dias RR, Benvenuti LA, and Stolf NAG, 2008. Thymic Cyst as a Differential Diagnosis of Acute Thoracic Aortic Disease. Rev Bras Cir Cardiovasc. Vol 23(4), pp:575-577.

9. Mueller DK, 2010. Thymic Tumors. Medscape - eMedicine Thoracic Surgery. (online), (http://emedicine.medscape.com/articl e/427197-overview

10. Duwe BV, Sterman DH, and Musani AI, 2005. Tumors of the Mediastinum. Chest. Vol128, pp:2893-2909.

11. Choi YW, McAdams HP, Jeon SC, Hong EK, Kim YH, Im JG, and Lee SR, 2001. Idiopathic Multilocular Thymic Cyst : CT features with Clinical and Histopathologic Correlation. AJR. Vol 177, pp:881885. 